\title{
Effect of nutritional intervention on the prevalence of metabolic syndrome and heart disease risk factors in urban Tehran (Tehran Lipid and Glucose Study)
}

\author{
A. Ramezankhani, ${ }^{7}$ P. Mirmiran ${ }^{7}$ and F. Azizi ${ }^{1}$
}

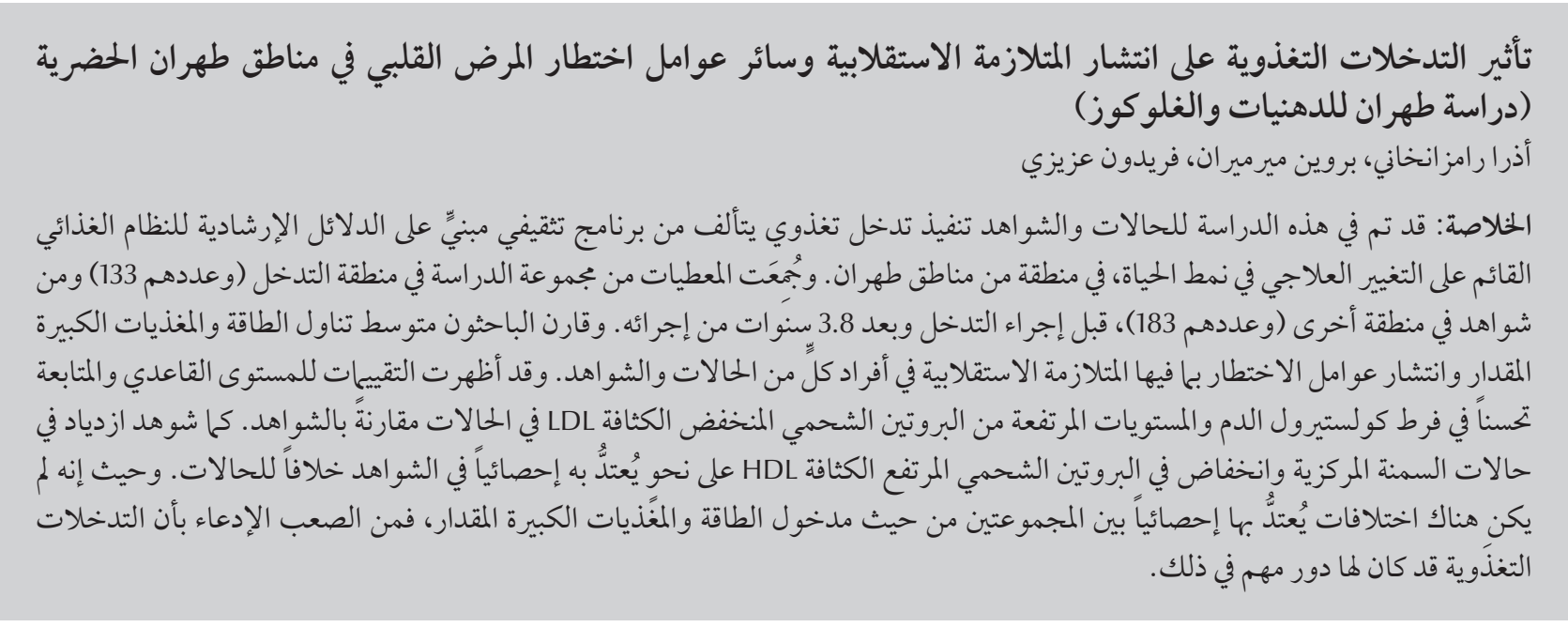

ABSTRACT In a case-control study a nutritional intervention consisting of an educational programme based on the Therapeutic Lifestyle Change diet (TLC) guidelines was implemented in one area of Tehran. Data were collected from subjects in the intervention area $(n=133)$ and controls from another area $(n=183)$, before and 3.8 years after the intervention. Mean energy and macronutrient intakes and prevalence of risk factors including metabolic syndrome were compared between and within cases and controls. Baseline and follow-up evaluations showed improvement in hypercholesterolemia and high LDL cholesterol levels in cases versus controls. Central obesity and low HDL cholesterol levels increased significantly in controls but not in cases. As there were no significant differences between the 2 groups in energy and macronutrient intakes, it is difficult to claim that nutritional interventions played an important role.

Effet d'une intervention nutritionnelle sur la prévalence du syndrome métabolique et sur les facteurs de risque de cardiopathie dans l'agglomération de Téhéran (étude sur le glucose et les lipides réalisée à Téhéran)

RÉSUMÉ Dans une étude cas-témoins, une intervention nutritionnelle consistant en un programme éducatif fondé sur les directives du régime de changement thérapeutique de style de vie a été mise en œuvre dans un district de la ville de Téhéran. Des données ont été recueillies auprès de sujets habitant le district de l'intervention ( $n=133)$ et de témoins résidant dans un autre district $(n=183)$, avant, puis 3,8 années après l'intervention. Les apports énergétiques moyens, les apports moyens en macronutriments et la prévalence des facteurs de risque, notamment le syndrome métabolique, ont été comparés entre les deux groupes et au sein de chaque groupe. Les évaluations du début de l'étude et pendant la période de suivi ont révélé des améliorations dans les taux d'hypercholestérolémie et de cholestérol des lipoprotéines de basse densité pour les sujets ayant bénéficié de l'intervention par rapport aux témoins. L'obésité abdominale et les faibles taux de cholestérol des lipoprotéines de haute densité avaient augmenté de manière importante chez les témoins mais n'avaient pas augmenté dans le groupe sous intervention. En l'absence de différences significatives entre les deux groupes pour les apports énergétiques et les apports en macronutriments, il est difficile d'affirmer que les interventions nutritionnelles jouent un rôle important. 


\section{Introduction}

Although significant reductions have occurred in the incidence of cardiovascular disease (CVD) since the mid1970s, this is still the primary cause of morbidity and mortality in many countries [1]. Recent studies in the Islamic Republic of Iran have shown an increasing mortality from CVD, and have found it to be a major health problem which imposes a high burden of disease on the health system [2-5]. It has been shown that hypertension, hyperlipidaemia, impaired glucose tolerance and diabetes, smoking, and stress are powerful risk factors for CVD. Previous studies in the Tehran Lipid and Glucose study (TLGS) population showed $22 \%$ of men and $24 \%$ of women were hypertensive; $23 \%$ of the total population were hypercholestrolaemic and $4 \%$ were hypertriglyceridaemic [6]. Most of these risk factors are linked to lifestyle, in conjunction with excess calorie intake, increased dietary fat consumption and decreased physical activity [7-10]. Additionally, individuals with the metabolic syndrome are at high risk of coronary heart disease.

The metabolic syndrome is defined as a pattern of disturbances including central obesity, insulin resistance and hypertriglyceridaemia, dyslipidaemia and hypertension [11]. A recent study showed that the metabolic syndrome is highly prevalent in Tehrani adults, with an estimated prevalence of over $30 \%$ [12], which is higher than that in most developed countries such as the United States of America [13]. It is thought that genetic, metabolic and environmental factors, including diet, play an important role in its development [14]. The high prevalence of noncommunicable diseases has led to many countries implementing mechanisms for the prevention of these diseases, of which lifestyle modification is a major one $[15,16]$. Modifications of dietary pattern and increased physical activity have been shown to lead to a reduction in metabolic syndrome and other CVD risk factors $[11,17]$. The present data indicates a shortage of appropriate intervention programmes in the Islamic Republic of Iran [18], and hence this study was conducted to investigate the effectiveness of a nutritional intervention on the prevalence of metabolic syndrome and other CVD risk factors among adults in Tehran.

\section{Methods}

The current study was conducted within the framework of the TLGS, a prospective study of a representative sample of residents of district 13 of Tehran, performed to ascertain the prevalence of noncommunicable disease risk factors and developing a healthy lifestyle to curtail these risk factors [18].

\section{Subjects}

Residents in district 13 are covered by 3 health care centres. For the TLGS, 15005 people $\geq 3$ years were selected by a multistage cluster, random sampling method. For the case-control study reported here, nutritional interventions were implemented for the population covered by one of the health care centres. The remaining populations in the areas covered by the other 2 centres had no nutritional interventions and served as controls. The area of the intervention group was far from the areas where the control subjects lived. Interactions involving schooling, shopping and gatherings were estimated to be $<5 \%$ between the intervention and control groups.

The first dietaryassessment was done during 1999 to 2002 and the second during 2002 to 2005 . For the first assessment a representative sample of 1474 people aged $\geq 3$ years was randomly selected from the 3 areas. After 3.9 years, biochemical, anthropometric and dietary assessments were done in all these subjects. Pregnant women and subjects who had used hypoglycaemic agents, lipid-lowering and anti-hypertensive prescription medications were excluded from the study. Subjects $>20$ years old with relevant data were included in the study. Finally, 316 subjects remained and were divided into 2 groups according to area of residence (133 cases and 183 controls).

All subjects signed voluntary consent forms. The protocol for the study was approved by the research council of the Endocrine Research Centre of Shahid Beheshti University of Medical Sciences.

\section{Nutritional intervention}

The nutritional intervention consisted of an educational programme according to the Therapeutic Lifestyle Change diet (TLC) guidelines which were developed by the US National Heart, Lung, and Blood Institute for the National Cholesterol Education Program [19]. The TLC diet is a low saturated fat $(<7 \%$ of total caloric intake) and low cholesterol $(<200 \mathrm{mg}$ of dietary cholesterol a day) diet that emphasizes grains, cereals, legumes, vegetables, fruits, lean meats, poultry, fish and non-fat dairy products. According to the TLC, $25 \%-35 \%$ of the day's total calories should be from fat, and persons who are overweight or obese with dyslipidaemia should reduce their body weight through a combination of physical activity, total calorie reduction and behaviour therapy modifications.

This programme was introduced for all individuals aged $3+$ years in health care centres, schools and public places in intervention areas. At health care centres, family members were invited in turn to the centre, and were educated with a face-to-face approach between the educators and the participants. In schools, the intervention was conducted through direct education by trained teachers, parent-teacher cooperation societies and group-based activities such as fairs and competitions. Foods provided by school buffets or canteens were changed according to nutritional guidelines. Pamphlets and posters with 
related information were mailed every 2-4 months to family members, and lectures and discussion sessions were arranged in public places.

\section{Data collection}

The study population was interviewed privately, face-to-face. Trained interviewers using pretested questionnaires conducted interviews and all variables were assessed at baseline and at followup in both groups after 3.8 years.

\section{Assessment of dietary intake}

Dietary intake assessment was undertaken by 2-day 24-hour recall, administered to the subjects by expert interviewers who had experience in the Nationwide Food Consumption Survey project [20]. The first day recall was performed at subject's homes and the second day recall at a clinic visit in the dietary unit of TLGS within 1-3 days of the first visit. These 2 days aimed to be among typical eating days for subjects. Standard reference tables were used to convert household portions to grammes for computerization [21]. Following coding of diaries, the dietary recall form was linked to the Nutritionist III foods nutrient database, version 7.0 designed for Iranians (N-Squared Computing) and daily intakes of carbohydrates, proteins and fats for each individual were determined from the means of the 2 $\times 24$-hour dietary recalls.

\section{Assessment of other variables}

Blood pressure was measured using a standard mercury sphygmomanometer. Participants were made to rest for $15 \mathrm{~min}$ before their blood pressure was measured. A qualified physician measured the blood pressure of the seated subject twice; the mean of the 2 measurements was considered as the participant's blood pressure.

Weight was measured while the subjects were minimally clothed without shoes using digital scales and recorded to the nearest $100 \mathrm{~g}$. Height was measured in a standing position, without shoes using a tape measure while the shoulders were in a normal position. Waist circumference was measured at the narrowest level [22]. Body mass index (BMI) was calculated as weight divided by height squared $\left(\mathrm{kg} / \mathrm{m}^{2}\right)$.

Additional covariate information regarding age, sex, education, marital status and job was obtained using validated questionnaires.

A blood sample was drawn into vacutainer tubes from all subjects between 07.00 and 09.00 hours after 12-14 hours overnight fasting [23]. The samples were centrifuged $30-45 \mathrm{~min}$ after collection. All blood lipid analyses were done at the TLGS research laboratory on the day of blood collection. The analysis of samples was performed using the Selectra 2 autoanalyser (Vital Scientific). Fasting plasma glucose was measured on the day of blood collection by the enzymatic colorimetric method using glucose oxidase. Serum total cholesterol and triglyceride concentration were measured by commercially available enzymatic reagents (Pars Azmoon) adapted to the Selectra autoanalyser. High-density lipoprotein (HDL) cholesterol was measured after precipitation of the apolipoprotein B-containing lipoproteins with phosphotungstic acid. Low-density lipoprotein (LDL) cholesterol was calculated according to the method of Friedewald [24]. It was not calculated when the serum concentration of triacylglycerol was $>400 \mathrm{mg} /$ $\mathrm{dL}$. All samples were analysed when internal quality control met the acceptable criteria. Inter-assay and intra-assay coefficients of variation were $2.0 \%$ and $0.5 \%$ for total cholesterol and $1.6 \%$ and $0.6 \%$ for triacylglycerol respectively.

\section{Definition of terms}

The following definitions were used: obesitywas $\mathrm{BMI} \geq 30 \mathrm{~kg} / \mathrm{m}^{2}[25]$; hypercholesterolaemia was total cholesterol $\geq$ $240 \mathrm{mg} / \mathrm{dL}$; high LDL cholesterol was $\geq 160 \mathrm{mg} / \mathrm{dL}$ [26]; diabetes was fasting plasma glucose concentration $\geq 126$ $\mathrm{mg} / \mathrm{dL}$ or 2-h postchallenge glucose concentration of $\geq 200 \mathrm{mg} / \mathrm{dL}$ [27]; and hypertension was systolic blood pressure $\geq 140 \mathrm{mmHg}$ or diastolic blood pressure $\geq 90 \mathrm{~mm} \mathrm{Hg}$ or current use of antihypertensive medication [28]. Diagnosis of metabolic syndrome as recommended by the Adult Treatment Panel (ATP) III criteria was based on having at least 3 of the following 5 components: (1) waist circumference $>102 \mathrm{~cm}$ in men and $>88 \mathrm{~cm}$ in women; (2) serum HDL cholesterol $<40 \mathrm{mg} / \mathrm{dL}$ in men and $<50 \mathrm{mg} / \mathrm{dL}$ in women; (3) serum triacylglycerol concentrations $>150$ $\mathrm{mg} / \mathrm{dL}$; (4) blood pressure $>130 / 85$ $\mathrm{mmHg}$; and (5) fasting plasma glucose concentration $>110 \mathrm{mg} / \mathrm{dL}$ [26].

\section{Statistical methods}

All data were analysed using SPSS, version 9.05. Mean energy and macronutrient intakes were measured and compared within the 2 groups using the paired $t$-test. Analysis of covariance (ANCOVA) was used to compare the means between the 2 groups after controlling for age, sex and baseline variables. The chi-squared test was performed to compare the prevalence of risk factors and metabolic syndrome between the 2 groups after interventions. Mantel-Haenszel test was used to compare the prevalence of risk factors and metabolic syndrome between the 2 groups after controlling for age, sex and baseline variables. McNemar test was used to assess the change of risk factors status and metabolic syndrome, pre- and post-intervention.

\section{Results}

The mean age was 42.1 [standard deviation $(\mathrm{SD})$ 11.9] years in controls (73 men and 110 women), and 40.6 (SD 10.7) years in cases (61 men and 72 women).

The mean values for macronutrient intakes of the 2 groups are shown in Table 1 . The reported mean daily intakes of energy, carbohydrate and fat decreased significantly, whereas cholesterol and 
protein as percentages of total energy increased significantly in both groups. Mean protein intake increased and fat as percentage of total energy decreased significantly in controls. After adjusting for age, sex and baseline variables, no significant differences regarding macronutrients and energy intakes were observed between the case and control groups.

The prevalence of the risk factors and metabolic syndrome at baseline and follow-up in the 2 groups are shown in Table 2. The prevalence of low HDL cholesterol increased significantly in controls (from 39.9\% to 60.4\%) between baseline and follow-up measurements whereas in cases the increase was not significant (from $49.2 \%$ to $57.6 \%)(P<$ 0.01 ). Abdominal obesity also increased significantly in controls (from 26.2\% to $38.3 \%$ ) while in cases the increase was not significant (from $30.1 \%$ to $37.6 \%$ ) $(P<0.01)$. The prevalence of high LDL cholesterol did not change in controls over the period (19.2\% versus $18.9 \%$ respectively) whereas in the cases exposed to the educational intervention it decreased significantly from $21.7 \%$ to $9.5 \%$ $(P<0.05)$. After adjusting for age, sex and baseline variables, the same results were obtained $(P<0.05)$. The decrease in the rate of hypercholesterolemia was small in the controls (from 18.6\% to $13.2 \%)$ but was significant in the cases (from $18.3 \%$ to $8.3 \%)(P<0.01)$. There were no significant differences between the 2 groups regarding the prevalence of metabolic syndrome at baseline and follow-up in controls (24.6\% versus $30.2 \%$ respectively) and cases $(28.7 \%$ versus $29.8 \%$ respectively).

The distribution of subjects with regard to changes in risk factor status and metabolic syndrome at baseline and follow-up is shown in Table 3. In controls, $45.0 \%$ of subjects (49/109) who had normal HDL cholesterol at baseline had low HDL cholesterol at follow-up; whereas $16.4 \%$ (12/73) of subjects who had low HDL cholesterol at baseline showed normal levels in the follow-up assessment. These changes were significant $(P<0.01)$. Also $20.7 \%$ of controls (28/135) who did not have abdominal obesity at baseline developed abdominal obesity at follow-up, whereas $12.5 \%(6 / 48)$ of cases who had abdominal obesity at baseline became normal status after exposure to the intervention $(P<0.01)$. In the cases, $1.9 \%$ $(2 / 106)$ of subjects who had normal cholesterol at baseline developed hypercholesterolaemia after the intervention, whereas $62.5 \%(15 / 24)$ of those with hypercholesterolaemia at baseline showed normal cholesterol at follow-up $(P<0.01)$. Moreover, 3.3\% (3/90) of cases who had normal LDL cholesterol at baseline developed high LDL cholesterol in the follow-up measurement after the intervention; whereas $65.2 \%$ $(15 / 23)$ of cases who had high LDL cholesterol at baseline, showed normal levels after the intervention $(P<0.01)$. In controls $12.5 \%$ of individuals with normal triglycerides developed high hypertriglyceridaemic and $52.6 \%$ of hypertriglyceridaemic individuals returned to normal in the follow-up measurement, whereas in the cases $35.7 \%$ of hypertriglyceridaemic subjects became normal.

\section{Discussion}

This study, conducted in an urban population of Tehran, showed that the prevalence of several risk factors for CVD improved between the baseline and the follow-up measurements 3.8 years later. The prevalence of high LDL cholesterol did not change in controls whereas in the cases exposed to the educational intervention it decreased significantly. The prevalence of low HDL cholesterol increased significantly in controls between baseline and followup measurements whereas in cases the increase was not significant. Abdominal obesity also increased in controls while in cases the increase was not significant. The decrease in the rate of hypercholesterolemia was small in the controls but significant in the cases.

\begin{tabular}{|c|c|c|c|c|}
\hline \multirow[t]{3}{*}{ Variables } & \multicolumn{2}{|c|}{ Controls $(n=182)$} & \multicolumn{2}{|c|}{ Cases $(n=133)$} \\
\hline & Baseline & Follow-up & Baseline & Follow-up \\
\hline & Mean (SD) & Mean (SD) & Mean (SD) & Mean (SD) \\
\hline Total energy (kcal/dL) & $2327(810)$ & $2155(673)^{\mathrm{a}}$ & $2452(705)$ & $2245(664)^{a}$ \\
\hline Carbohydrate (g/dL) & 345 (117) & $320(99)^{\mathrm{a}}$ & 367 (110) & $333(106)^{\mathrm{a}}$ \\
\hline Protein $(\mathrm{g} / \mathrm{dL})$ & $65(24)$ & $69(27)^{b}$ & $70(22)$ & $72(32)$ \\
\hline Fat $(\mathrm{g} / \mathrm{dL})$ & $80(40)$ & $71(32)^{\mathrm{a}}$ & $81(33)$ & $72(29)^{b}$ \\
\hline Carbohydrate (\% of total energy) & $59.1(7.4)$ & $58.8(9.1)$ & $59.3(6.9)$ & $59.1(7.5)$ \\
\hline Protein (\% of total energy) & $11.2(2.1)$ & $12.7(3.4)^{\mathrm{c}}$ & $11.4(1.7)$ & $12.9(4.7)^{\mathrm{c}}$ \\
\hline Fat (\% of total energy) & $29.8(7.8)$ & $28.1(7.4)^{\mathrm{b}}$ & $29.2(6.9)$ & $28.5(8.8)$ \\
\hline Cholesterol (mg/dL) & 130 (115) & $219(150)^{c}$ & $164(159)$ & $199(113)^{\mathrm{b}}$ \\
\hline
\end{tabular}

${ }^{a} \mathrm{P}<0.01 ;{ }^{b} \mathrm{P}<0.05 ;{ }^{c} \boldsymbol{P}<0.001$ comparing baseline and follow-up data using analysis of covariance test adjusted for age, sex and baseline of each variable. $S D=$ standard deviation. 
Several studies have shown the prevalence of hypercholesterolaemia and hypertriglyceridaemia declined significantly after nutritional interventions, in both sexes and among different races [29-31]. In contrast, the National Healthy Lifestyle Programme in Singapore, implemented in 1992, was unsuccessful in reducing total blood cholesterol levels [32]. An intervention study in England that was a part of a World Health Organization project was conducted on 18210 workers in 24 factories. Subjects were followed for 5 years, and only $4 \%$ reduction in CVD risk factors was seen [33].

In the present study, despite significant decreases in energy, carbohydrate and fat intake between baseline and follow-up in both groups, the prevalence of low HDL cholesterol increased significantly only in controls. Other studies have shown that HDL cholesterol level is less affected by nutritional factors [34], and more affected by BMI, physical activity, smoking, alcohol and some hormones [35]. The significant increase in the prevalence of abdominal obesity in controls may be responsible for the change. On the other hand, the difference of the prevalence of low HDL cholesterol between the 2 groups may be due in part to differences in physical activity and other confounding factors. We did not measure physical activity data since the reliability and validity of the Lipid Research Clinic questionnaire that was used in the TLGS had not been evaluated in our country. The availability of valid data for this confounding variable could have helped to provide a better understanding of this difference of low HDL cholesterol between the 2 groups.

In this study the prevalence of high LDL cholesterol and total cholesterol decreased significantly in the intervention group, despite significant increases in cholesterol intake and decreases in total fat in both groups. It has been shown that high cholesterol intake leads to higher LDL cholesterol levels [36], whereas some studies have found that the effect of saturated fatty acid on serum cholesterol is more important than dietary cholesterol. Interestingly, other experimental studies have found that, when combined, cholesterol intake and saturated fatty acids synergistically promote the elevation of LDL cholesterol [37]. Furthermore, it has been shown that age, obesity, physical activity, some diseases, poly- and mono-unsaturated fatty acids, the type of carbohydrate and some micronutrients affect serum cholesterol levels [38-41]. Further research assessing these factors will provide stronger evidence of this relationship.

The data on changes in individuals' CVD risk status showed that in controls a high proportion of individuals 


\begin{tabular}{|c|c|c|c|c|c|c|c|c|c|c|}
\hline \multirow[t]{3}{*}{ Risk factor ${ }^{a}$} & \multicolumn{5}{|c|}{ Controls $(n=182)$} & \multicolumn{5}{|c|}{ Cases $(n=133)$} \\
\hline & \multicolumn{2}{|c|}{ Deteriorated $^{b}$} & \multicolumn{2}{|c|}{ Improved $^{\mathrm{c}}$} & \multirow[t]{2}{*}{$P$-value ${ }^{\text {d }}$} & \multicolumn{2}{|c|}{ Deteriorated $^{\mathbf{b}}$} & \multicolumn{2}{|c|}{ Improved $^{\mathrm{c}}$} & \multirow[t]{2}{*}{$P$-value ${ }^{\mathrm{d}}$} \\
\hline & No. & $\%$ & No. & $\%$ & & No. & $\%$ & No. & $\%$ & \\
\hline Diabetes & 5 & 2.8 & 0 & 0.0 & 0.06 & 1 & 0.8 & 0 & 0.0 & 1.00 \\
\hline Hypertriglyceridaemia & 18 & 12.5 & 20 & 52.6 & 0.87 & 9 & 8.8 & 10 & 35.7 & 1.00 \\
\hline Hypercholestrolaemia & 11 & 7.4 & 21 & 61.8 & 0.11 & 2 & 1.9 & 15 & 62.5 & 0.002 \\
\hline High LDL cholesterol & 16 & 11.0 & 17 & 48.6 & 1.00 & 3 & 3.3 & 15 & 65.2 & 0.008 \\
\hline Low HDL cholesterol & 49 & 45.0 & 12 & 16.4 & 0.001 & 24 & 36.4 & 14 & 22.2 & 0.143 \\
\hline Hypertension & 10 & 6.3 & 11 & 55.0 & 1.00 & 5 & 4.6 & 12 & 60.0 & 0.143 \\
\hline Obesity & 9 & 6.8 & 4 & 10.2 & 0.26 & 5 & 5.0 & 3 & 11.5 & 0.72 \\
\hline Abdominal obesity & 28 & 20.7 & 6 & 12.5 & 0.001 & 19 & 20.4 & 9 & 22.5 & 0.08 \\
\hline Metabolic syndrome & 25 & 18.5 & 15 & 34.1 & 0.15 & 15 & 16.5 & 14 & 38.9 & 1.00 \\
\hline
\end{tabular}

${ }^{a}$ Using standard international criteria [24-27].

${ }^{b}$ Deteriorated $=$ number of subjects who were normal at baseline, abnormal at follow-up; \% of abnormal/normal subjects. 'Improved = number of subjects who were abnormal at baseline, normal at follow-up; \% of normal/abnormal subjects.

${ }^{d}$ Comparison between baseline and at follow-up using McNemar test.

$L D L=$ low-density lipoprotein; $H D L=$ high-density lipoprotein.

who were normal at baseline developed low HDL cholesterol, whereas fewer individuals with low HDL cholesterol at baseline became normal in the followup measurement. As mentioned before, this may be attributed to the increased prevalence of abdominal obesity in this group. More of the controls improved their hypertriglyceridaemic status from abnormal to normal than did cases. Although not significant, the changes are an interesting finding.

Despite decreased energy, carbohydrate and fat intakes in both groups, modulation of triglyceride status in controls was greater than in cases. This may be due to a significant decrease in the percentage of energy obtained from fat. As demonstrated in a recent study, decreases in the percentage of energy from fat intake could potentially decrease serum triglyceride levels [42]. Furthermore, limited saturated fatintake, modified carbohydrate intake, decreased alcohol drinking, stopping smoking and increased physical activity result in favourable lipid profiles $[43,44]$.

There were no significant differences between the 2 groups regarding the prevalence of metabolic syndrome at baseline and follow-up in controls and cases. The metabolic syndrome is well established as a problem condition, and is associated with the development of atherosclerosis and increased CVD risk. Moreover, there is extensive scientific evidence, especially in countries with better and longer term national health programmes, that the prevalence of metabolic syndrome has increased in the last decade, which suggests that the disease burden (including type 2 diabetes) has increased as well [45]. Obesity and sedentary lifestyle, coupled with unhealthy diet and genetic factors, are believed to interact to produce metabolic syndrome. In recent decades, several epidemiological studies have underlined the relation between diet and incidence of coronary heart disease and other diseases. Dietary factors exert their influence largely through their effects on blood lipids and lipoproteins, as well as on other established modifiable risk factors, with the exception of cigarette smoking [44-46]. Our findings did not support the hypothesis that nutritional intervention is associated with a significant reduction in the risk of developing metabolic syndrome. The ATP III highlighted the importance of diagnosing and treating metabolic syndrome, focusing on increasing physical activity, lowering excess body fat and on modifying specific dietary patterns [45]. We therefore believe that the physical activity of individuals in both controls and cases in our study may have been insufficient. As we did not measure physical activity level, it is difficult to confirm this theory.

There were some limitations to the current study. We did not find substantial differences in the measures of nutrient and energy intake between the 2 groups. This may be attributed to the 24-hour recall method used for data collection. Problems commonly associated with this method include: an inability to recall accurately the kinds and amounts of food eaten, difficulty in determining whether the day being recalled represents an individual's typical intake and the tendency for persons to over-report low intakes and underreport high intakes of foods. Furthermore, the study was a community field trial and it was not possible educate all individuals about nutrition face-toface. Some trials have shown that this approach is the most successful intervention programne in schools, health centres and work places [47-49]. The short duration of interventions in this study may also have been a factor, as recent studies have shown that lifestyle 
modification, especially dietary patterns, need longer-term interventions $[50,51]$.

In summary, this study showed modulation of some CVD risk factors in cases exposed to an educational intervention compared with controls. As there was no significant difference between the 2 groups regarding energy and macronutrient intakes, it is hard to claim that nutritional interventions played an important role. Our data therefore raise the possibility that other lifestyle choices are important in the modulation of certain CVD risk factors.

\section{Acknowledgements}

The authors thank the participants of the Tehran Lipid and Glucose Study and the staff of the Research Institute of
Endocrine sciences and the TLGS unit, for their valuable help in conducting this study. This study was supported by grant no. 121 from the National Research Council of the Islamic Republic of Iran, and by the combined support of the National Research Council of the Islamic Republic of Iran and Research Institute of Endocrine sciences of Shaheed Beheshti University of Medical Sciences.

\section{References}

1. Burchfiel $\mathrm{CM}$ et al. Cardiovascular risk factors and hyperinsulinemia in elderly men: the Honolulu Heart Program. Annals of Epidemiology, 1996, 6:490-497.

2. Sarraf-Zadegan $\mathrm{N}$ et al. Secular trends in cardiovascular mortality in Iran, with special reference to Isfahan. Acta Cardiologica, 1999, 54:327-333.

3. Sarraf-Zadegan $\mathrm{N}$ et al. The prevalence of coronary artery disease in an urban population in Isfahan, Iran. Acta Cardiologica, 1999, 54:257-263.

4. Ghassemi H, Harrison G, Mohammad K. An accelerated nutrition transition in Iran. Public Health Nutrition, 2002, 5 1A;149-155.

5. Kimiagar SM et al. Food consumption pattern in the Islamic Republic of Iran and its relation to coronary heart disease. Eastern Mediterranean Health Journal, 1998, 4:539-547.

6. Azizi F et al. Distribution of blood pressure and prevalence of hypertension in Tehran adult population: Tehran Lipid and Glucose Study (TLGS), 1999-2000. Journal of Human Hypertension, 2002, 16:305-312.

7. Keys A. Coronary heart disease-the global picture. Atherosclerosis, 1975, 22:149-192.

8. Kuller LH. Epidemiology of cardiovascular diseases: current perspectives. American Journal of Epidemiology, 1976, 104:425-496.

9. Stamler J. Epidemiology of coronary heart disease. Medical Clinics of North America, 1973, 57:5-46.

10. Stamler J. George Lyman Duff Memorial Lecture. Lifestyles, major risk factors, proof and public policy. Circulation, 1978, 58:3-19.

11. Panagiotakos DB et al. Impact of lifestyle habits on the prevalence of the metabolic syndrome among Greek adults from the ATTICA study. American Heart Journal, 2004, 147:106-112.

12. Azizi $\mathrm{F}$ et al. Prevalence of metabolic syndrome in an urban population: Tehran Lipid and Glucose Study. Diabetes Research and Clinical Practice, 2003, 61:29-37.

13. Ford ES, Giles WH, Dietz WH. Prevalence of the metabolic syndrome among US adults: findings from the third National Health and Nutrition Examination Survey. Journal of the American Medical Association, 2002, 287:356-359.

14. Hollenberg NK. Genetic versus environmental etiology of the metabolic syndrome among male and female twins. Current Hypertension Reports, 2002, 4:178.

15. First WHO food and nutrition action plan for Europe 2000-2005. Plans for 2000-2001. Copenhagen, World Health Organization Regional Office for Europe, 2000.
16. Leparski E, Nussel E. CINDI, countrywide integrated noncommunicable diseases intervention programme. In: Protocol and guidelines for monitoring and evaluation procedures. New York, World Food Programme, 1987.

17. Monzavi R et al. Improvement in risk factors for metabolic syndrome and insulin resistance in overweight youth who are treated with lifestyle intervention. Pediatrics, 2006, 117:e1111e1118.

18. Azizi F. Tehran Lipid and Glucose Study: rationale and design. CVD Prevention, 2000, 3:242-247.

19. Expert Panel on Detection, Evaluation, and Treatment of High Blood Cholesterol in Adults. Executive summary of the third report of the National Cholesterol Education Program (NCEP) Expert Panel on Detection, Evaluation, and Treatment of High Blood Cholesterol in Adults (Adult Treatment Panel III). Journal of the American Medical Association, 2001, 285:2486-2497.

20. Kimiagar M. [National food consumption survey]. Tehran, National Nutrition and Food Technology Research Institute, 1995 [in Farsi].

21. Ghaffarpour M, Houshiar-Rad A, Kianfar H. The manual for household measures, cooking yield factors and edible portion of foods. Tehran, Keshaverzi Press, 1999.

22. Mirmiran P, Esmaillzadeh A, Azizi F. Detection of cardiovascular risk factors by anthropometric measures in Tehranian adults: receiver operating characteristic (ROC) curve analysis. European Journal of Clinical Nutrition, 2004, 58:1110-1118.

23. Azizi F et al. Serum lipid levels in an Iranian adults population: Tehran lipid and glucose study. European Journal of Epidemiology, 2003, 18:311-319.

24. Friedewald WT, Levy RI, Fredrickson DS. Estimation of the concentration of low-density lipoprotein cholesterol in plasma, without use of the preparative ultracentrifuge. Clinical Chemistry, 1972, 18:499-502.

25. National Institutes of Health. Clinical guidelines on the identification, evaluation, and treatment of overweight and obesity in adults-the evidence report. Obesity Research, 1998, 6(Suppl. 2);51S-209S.

26. National Cholesterol Education Program (NCEP) Expert Panel on Detection, Evaluation, and Treatment of High Blood Cholesterol in Adults (Adult Treatment Panel III). Third report of the National Cholesterol Education Program (NCEP) Expert Panel on Detection, Evaluation, and Treatment of High Blood Cholesterol in Adults. Circulation, 2002, 106:3143-3421.

27. Expert Committee on the Diagnosis and Classification of Diabetes Mellitus. Report of the Expert Committee on the Di- 
agnosis and Classification of Diabetes Mellitus. Diabetes Care, 1997, 20:1183-1197.

28. Joint National Committee on Prevention, Detection, Evaluation, and Treatment of High Blood Pressure. The sixth report of the Joint National Committee on Prevention, Detection, Evaluation, and Treatment of High Blood Pressure. Archives of Internal Medicine, 1997, 157:2413-2446.

29. Harrell JS et al. A public health vs a risk-based intervention to improve cardiovascular health in elementary school children: the Cardiovascular Health in Children Study. American Journal of Public Health, 1999, 89:1529-1535.

30. Obarzanek E et al.; DISC Collaborative Research Group. Long-term safety and efficacy of a cholesterol-lowering diet in children with elevated low-density lipoprotein cholesterol: seven-year results of the Dietary Intervention Study in Children (DISC). Pediatrics, 2001, 107:256-264.

31. Haq IU et al. Population implications of lipid lowering for prevention of coronary heart disease: data from the 1995 Scottish health survey. Heart (British Cardiac Society), 2001, 86:289-295.

32. Cutter J, Tan BY, Chew SK. Levels of cardiovascular disease risk factors in Singapore following a national intervention programme. Bulletin of the World Health Organization, 2001, 79:908-915.

33. Head J, Fuller JH. International variation in mortality among diabetic patients: The WHO Multinational Study of Vascular Disease in diabetics. Diabetologia, 1990, 33:477-481.

34. Mann JI. Dietary effects on plasma LDL and HDL. Current Opinion in Lipidology, 1997, 8:35-38.

35. Krummel D. Nutrition in cardiovascular disease. In: Mahan LK Escott-Stump S, eds. Krauses food, nutrition, and diet therapy. Philadelphia, WB Saunders, 1996:558-595.

36. Krauss RM et al. AHA Dietary Guidelines: revision 2000: A statement for healthcare professionals from the Nutrition Committee of the American Heart Association. Circulation, 2000, 102:2284-2299.

37. Schaefer EJ, Brousseau ME. Diet, lipoproteins, and coronary heart disease. Endocrinology and Metabolism Clinics of North America, 1998, 27:711-732.

38. Pasternak RC et al. 27th Bethesda Conference: matching the intensity of risk factor management with the hazard for coronary disease events. Task Force 3. Spectrum of risk factors for coronary heart disease. Journal of the American College of Cardiology, 1996, 27:978-990.
39. Miyashita $\mathrm{Y}$ et al. Beneficial effect of low carbohydrate in low calorie diets on visceral fat reduction in type 2 diabetic patients with obesity. Diabetes Research and Clinical Practice, 2004, 65:235-241

40. Lichtenstein AH. Dietary fat, carbohydrate and protein: effects on plasma lipoprotein profiles fat, carbohydrate and protein and plasma lipids. Journal of Lipid Research, 2006, 47:1661-1667.

41. Oda H. Functions of sulfur-containing amino acids in lipid metabolism. Journal of Nutrition, 2006, 136(6 Suppl.):1666S1669 S.

42. Pejic RN, Lee DT. Hypertriglyceridemia. Journal of the American Board of Family Medicine, 2006, 19:310-316.

43. Castelli WP. Epidemiology of triglycerides: a view from Framingham. American Journal of Cardiology, 1992, 70:3H-9H.

44. Wing RR. Behavioral approaches to the treatment of obesity. In: Bray G, Bouchard C, James P, eds. Handbook of obesity. New York, Marcel Dekker, 1993:855-873.

45. Pitsavos $\mathrm{C}$ et al. The adoption of Mediterranean diet attenuates the development of acute coronary syndromes in people with the metabolic syndrome. Nutrition Journal, 2003, 2:1.

46. Klem ML et al. A descriptive study of individuals successful at long-term maintenance of substantial weight loss. American Journal of Clinical Nutrition, 1997, 66:239-246.

47. Puska P et al. The North Karelia Project: a programme for community control of cardiovascular diseases. Scandinavian Journal of Social Medicine, 1976, 4:57-60.

48. Pietinen $P$ et al. Changes in diet in Finland from 1972 to 1992: impact on coronary heart disease risk. Preventive Medicine, 1996, 25:243-250.

49. Pietinen $\mathrm{P}$ et al. Nutrition and cardiovascular disease in Finland since the early 1970s: a success story. Journal of Nutrition, Health \& Aging, 2001, 5:150-154

50. Cicero AF et al. Long-term effect of a dietary education program on postmenopausal cardiovascular risk and metabolic syndrome: the Brisighella Heart Study. Journal of Women's Health, 2010, 19(1):133-137.

51. Plachta-Danielzik S et al. Eight-year follow-up of school-based intervention on childhood overweight-the Kiel obesity prevention study. Obesity Facts, 2011, 4(1):35-43. 